\title{
Morphology of extruded and injection-moulded blends of PET/LDPE and PET/Ionomer
}

\author{
C.M.A. Lopes, M.C. Gonçalves, M.I. Felisberti \\ Institute of Chemistry - Universidade Estadual de Campinas \\ P.O. Box 6154 , Campinas- SP, 13084-862, Brazil \\ email:maria@iqm.unicamp.br
}

Due to the interesting properties and wide application potential of the resulting materials, polymer blending has become an important field in polymer research. When it comes to immiscible polymer blends, great attention is dedicated to the morphology, which is a consequence of the dispersion and mixing of the polymers during melt-compounding process [1]. This interest is justified because the type of morphology and the phase dimensions determine the properties of a blend [2]. The development of morphology of polymer blends is affected by several factors and is quite complex. An important parameter is the processing history and, although the final products are injection-moulded, most researches concern only with the morphology of the extruded blends.

In the present study, the morphology of extruded and injection-moulded 50/50 blends of recycled poly(ethylene terephthalate) (PET) with poly(ethylene-methacrylic acid) ionomer (Novex) and with low density polyethylene (LDPE) were compared. The blends were prepared in a twin screw extruder with $\mathrm{L} / \mathrm{D}$ ratio 8 at $100 \mathrm{rpm}$ and temperature ranging from 250 to $265{ }^{\circ} \mathrm{C}$. The extruded blends were then injection-moulded. The samples were cryogenically fractured parallel and perpendicular to the extrusion and injection flow direction. The fractured surfaces were coated with carbon and gold in a Bal-Tec Med 020 instrument and examined in a JEOL JSM-6340F fieldemission scanning electron microscope, working at an acceleration voltage of $3 \mathrm{kV}$. The identity of the phases was achieved through selective solubility in chlorosulfonic acid and average domain sizes were estimated by using the Image-Pro Plus 4.0 (media Cybernetics) software.

The extruded PET/LDPE and PET/ionomer blends (FIG. 1) present a PET dispersed phase morphology, according to selective solubility tests. The morphology changes completely when the blends are injection-moulded (FIG. 2). In both cases, the analysis of the parallel fracture shows the presence of fibre-like PET domains oriented in the direction of the injection flow. However, the perpendicular fractured surface shows that theses domains are interconnected, suggesting the occurrence of dual phase continuity.

The adhesion between the phases for the PET/LDPE blend is very poor when compared with the ionomer blend, where rather than fracturing at the surface of the dispersed phases, the fracture path cuts right through both phases. The specific interaction between ionomer and PET reduces the interfacial energy and consequently this blend presents a much finer morphology than the corresponding PET/LDPE blend [3].

[1] K. Wilczyński et al, J. Mat. Proc. Tech. 109 (2001) 320.

[2] L. A. Utracki, Polymer Blends and Alloys, Carl Hanser, Munich, 1991.

[3] This work was sponsored by FAPESP (96/2982-8) and CNPq (479749/01-9). The authors would like to thank ReciPET, Tetra Pak, and OPP for supplying the polymers. 


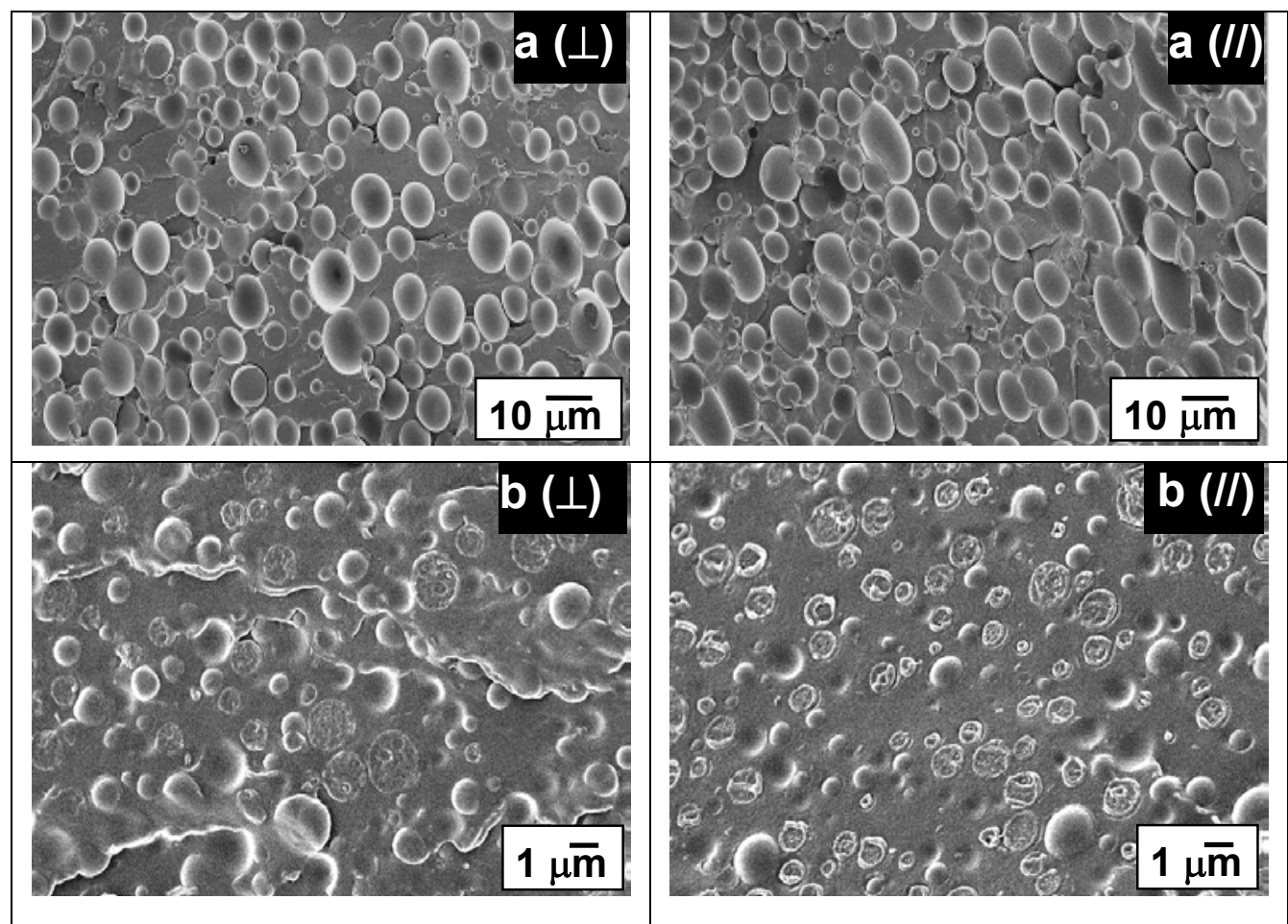

FIG. 1. FESEM micrographs of parallel and perpendicular cryo-fractured surfaces of 50/50 PET/LDPE (a) and PET/lonomer (b) extruded blends.
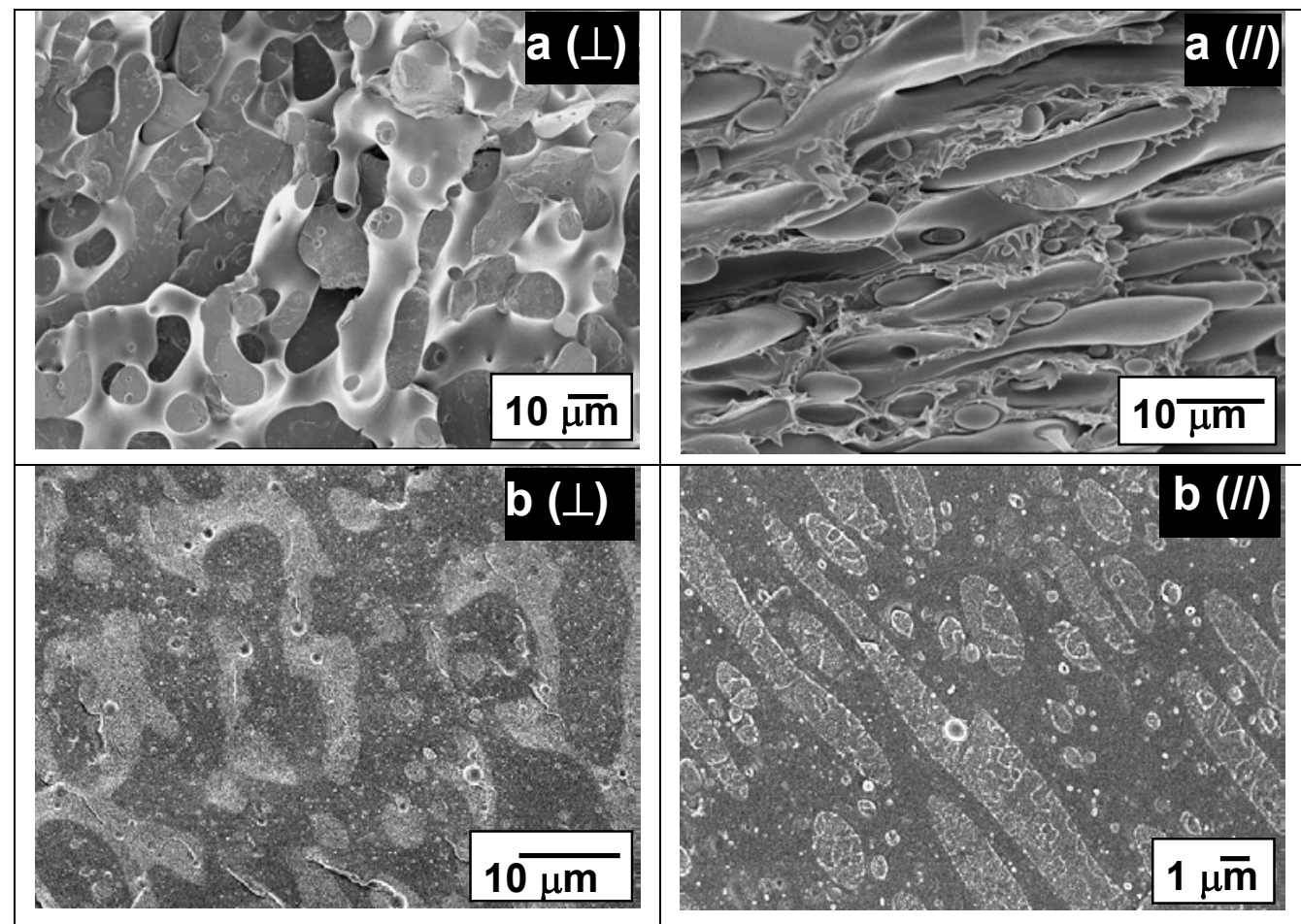

FIG. 2. FESEM micrographs of parallel and perpendicular cryo-fractured surfaces of 50/50 PET/LDPE (a) and PET/lonomer (b) injection-moulded blends. 